\title{
Efficacy of Forward Head Posture Treatment on Neck Function and Quality of Life
}

\author{
Hyun-Joong Kima ${ }^{a}$, Eunsang Lee ${ }^{a}{ }^{\circledR}$ \\ aDepartment of Physical Therapy, Gwangju Health University, Gwangju, Republic of Korea
}

Objective: Forward head posture can caused by deformation of structures and soft tissues around the neck, which has an uncomfortable effect on daily life as well as functional disorders of the neck. However, studies related to direct forward head posture, neck function, and quality of life have not yet been conducted.

Therefore, the purpose of this study is to investigate the effect of improving the forward head posture on the function of the neck and to examine the change in the quality of life.

Design: A randomized controlled trial

Methods: The participants were 41 adults $(22.17 \pm 2.67$ years) recruited and redivided randomly into two group (Biofeedback, BFG vs. Control). The Biofeedback group was proceeded according to the over load principle through 4 steps. $(n=21)$. The control $(n=20)$ was not applied after TENS padding was applied and 20 minute. This study was conducted three times a week for a total of four weeks.

Results: Forward head posture for showed significant improvement in the results in the craneocervical angle (p $<0.05,95 \%$ CI: $0.130,2.858)$. In neck disability index more significant improvement in BFG than group ( $p<0.05,95 \%$ CI: 14.346, 17.825), and BFG showed significant increased in the results in the Quality of life $(\mathrm{p}<0.05,95 \%$ CI: $0.392,9.549)$

Conclusions: This study suggected that forward head posture treatment and effective for neck function and quality of life

Key Words: Disability, Neck,Quality of life

서론

현대사회의 산업 발달에 따라 업무능률의 향상을 위해 각종 첨단 장비들이 일상에서 흔히 사용되고 있다. 각종 컴퓨터, 스마트폰 등의 발달로 통신분야 뿐만 아니라 여 러 분야에서 편리하게 사용되어지고 있다. 그러나 이런 장비들을 잘못된 자세로 사용할 경우 우리 신체의 근골격 계에 여러 가지 문제를 일으킬 수 있다[1]. 특히 목 부분 에 많은 문제를 일으킬수 있는데, 잘못된 자세는 비정상 적인 근수축과 기능장애를 일으킬 수 있으며[2], 대표적인 자세이상으로 전방 머리자세(Forward head posture, FHP)가 있다[3].

전방머리자세는 상부 목이 폄 되고 하부 목이 굽힘 되 어 머리가 체간보다 앞으로 나오는 자세를 말한다[4]. 전 방머리자세는 목 폄근(뒤통수 밑근, 목 반가시근, 목 널판 근, 위등세모근)과 목빗근의 단축, 그리고 목 굽힘근의 약
화를 동반하고 있다[5]. 이로 인해 목뼈 사이의 압박 증가 와 목 주변 압통점들을 유발 할 수 있다[6].

Cho 등[7]의 연구에 따르면 지속적인 전방머리자세는 정상인에 비해 목 근육의 피로도 증가를 보였고, 이 결과 로 머리의 불안정을 안정시키기 위한 목과 등 근육의 긴 장과 수축의 과도한 반복 현상이라고 보고하였다. 이러한 목 주변 구조 및 연부 조직의 변형은 목의 움직임에도 영 향을 미친다[8]. 결과적으로 목에서 하부근육의 신장이 일 어나고, 장기적으로 지속될 경우 목뼈의 정상적인 앞굽음 상실과 함께 목의 기능장애가 나타날 수 있다[8].

또한 전방머리 자세가 지속될 때 골격 정렬 변화를 가 져올수 있다. 이런 정렬변화는 근육의 단축과 신장, 주동 근과 길항근 사용강도의 불균형, 또는 근육의 변화를 촉 진하는 근골격계 손상을 동반하여 목 통증을 동반하며, 근 긴장도 증가, 통증, 기능 소실 등의 신경근 증상을 유 발하고 이로 인해 삶의 질까지 영향을 미칠 수 있다[9]. 
그러나 아직까지 직접적인 전방머리자세와 목의 기능, 삶의 질에 관련된 연구가 진행되지 않고 있다. 그래서 본 연구는 전방머리자세를 개선하여 목의 기능에 어떤 효과 가 있는지 알아보고 삶의 질의 변화를 알아보고자 한다.

\section{연구 방법}

\section{연구 대상}

본 연구에서는 실험의 목적과 방법의 설명을 충분히 들 은 후 실험 참여에 자발적으로 동의한 30 명의 대상자 중 에, 3 개월 이내 약이나 진통제를 투약한 자, 치료에 영향 을 미칠 수 있는 외과적 수술, 주사치료 또는 심한 목추간 판탈출증, 목골절환자 등을 제외 하였다

전방머리자세를 갖는 연구대상자를 선정하기 위해 척추 -두개각(Cranial Vertebral Angle, CVA)을 측정하여 $49^{\circ}$ 미만인 대상자를 선정하였고[10], 중재하기 위해 biofeedback 운동 21 명과 대조군 20 명 총 41 명의 대상자를 배정하였다.

본 실험은 2 개의 그룹에 4 주간 중재를 실시하였으며 실험군은 목 안정화 운동을 주3회 20 25분으로 실시하였 고, 대조군은 플라시보 효과를 위해 전기패드를 부착하여 4주간의 중재 후 사후측정을 실시하였다. 그에 따른 각 그룹 간 목의 기능과 삶의 질을 측정하여 어떤 효과가 있 는지 비교 분석하였다.

대상자들은 자발적 참여 의사를 밝힌 대상자들로 선정 하였고, 실험에 앞서 실험에 대한 충분한 이해를 돕기 위 해 자세한 설명을 하였다. 실험 참여 동의서에 서명 후 헬 싱키선언에 따른 윤리기준을 준수한 연구를 진행하였다.
중재 방법

\section{목 안정화 운동(Biofeedback exercise)}

Biofeedback을 활용한 목 안정화 운동은 자세의 정렬 을 향상시킬 수 있고, 통증을 가진 환자의 기능향상 및 통 증감소에 효과적이라고 보고되었다[11].

목 안정화운동은 Fernádez 등[11]의 연구를 참고하여 연구를 참고하여 연구를 진행하였다. 공기를 체운 에어백 을 뒤통수 뼈 밑에 놓고, $20 \mathrm{mmHg}$ 로 맞추어 놓는다. 대 상자에게 턱을 당기면서 에어백을 누르라고 지시하여 목 의 깊은 목근육이 수축 되도록 한다. 처음에는 $20 \mathrm{mmHg}$ 에서 시작하고, 최종단계는 $30 \mathrm{mmHg}$ 를 목표로 설정한 다. 최종단계에 도달하기 위해 $2 \mathrm{mmHg}$ 의 강도로 단계적 으로 올리면서, $22 \mathrm{mmHg}-24 \mathrm{mmHg}-26 \mathrm{mmHg}-$ $28 \mathrm{mmHg}-30 \mathrm{mmHg}$, 운동을 수행한다. 점증 부하원리 에 의해, 1 주째는 구심성과 원심성수축을 반복 하고, 2 주 째는 구심성 수축 후 등척성 수축 3 초유지, 그리고 원심 성 수축을 실시하였다. 3 주째는 구심성 수축과 원심성 수 축을 반복, 4 주째는 구심성 수축 후 등척성 수축 3 초 유 지, 그리고 원심성 수축을 실시하였다. 처음 2 주간은 20 $\mathrm{mmHG} \sim 26 \mathrm{mmHG}$ 의 강도로, 3 4주간은 $26 \mathrm{mmHG}$ $30 \mathrm{mmHG}$ 의 강도를 환자들에게 사전에 운동방법을 숙지 시킨 후 1,3 주는 20 회 3 세트, 2,4 주는 15 회 3 세트를 실시 하였고, 세트 사이 휴식시간은 15 초로 설정하여 20 분씩, 4주 동안 주3회, 총 12회 실시하였다(Table 2).

Table 1. General Characteristics of Participants $\quad(n=41)$

\begin{tabular}{llll}
\hline Characteristics & Biofeedback $\left(\mathbf{n}_{\mathbf{1}=21}\right)$ & Control $\left(\mathbf{n}_{\mathbf{2}}=\mathbf{2 0}\right)$ & $\mathbf{t} / \mathbf{( p )}$ \\
\hline Gender $($ meal/female) & $7 / 14$ & $6 / 14$ & $0.053(0.543)$ \\
Age $($ years $)$ & $22.91(2.84)$ & $21.40(2.30)$ & $1.856(0.071)$ \\
Height $(\mathrm{cm})$ & $167.0(7.20)$ & $166.98(9.18)$ & $0.395(0.695)$ \\
Weight $(\mathrm{kg})$ & $60.24(10.85)$ & $61.77(13.05)$ & $-0.408(0.685)$ \\
CVA baseline $\left(^{\circ}\right)$ & $47.54(0.83)$ & $47.37(2.08)$ & $0.573(0.570)$ \\
\hline
\end{tabular}

The values are presented mean $(\mathrm{SD})^{\mathrm{a}}$

CVA: cranial vertebral angle.

Table 2. Biofeedback exercise programs

\begin{tabular}{|c|c|c|c|}
\hline & Intensity & time & Methods \\
\hline 1st wk & $22-26 \mathrm{mmHg}$ & 3 set, 20 repeats & concentric and eccentric contractions ( $3 \mathrm{sec})$ \\
\hline 2 st wk & $22-26 \mathrm{mmHg}$ & 3 set, 15 repeats & concentric ( $3 \mathrm{sec})$ and isometric contractions ( $5 \mathrm{sec})$, eccentric, contractions ( $3 \mathrm{sec})$ \\
\hline 3 st wk & 26-30 mmHg & 3 set, 20 repeats & concentric and eccentric contractions ( $3 \mathrm{sec}$ ) \\
\hline 4 st wk & $26-30 \mathrm{mmHg}$ & 3 set, 15 repeats & concentric ( $3 \mathrm{sec})$ and isometric contractions ( $5 \mathrm{sec})$, eccentric, contractions ( $3 \mathrm{sec})$ \\
\hline
\end{tabular}




\section{대조군(Control)}

대조군은 플라시보 효과(Placebo effect)를 사용한 중 재를 적용하였으며, 중재는 TENS(Intelect Advanced Color Cambo with EMG, KOASTRON, USA)를 사용하였다. 피부부착 전극은 스펀지 재질로 $5 \times 5$ 크기의 원형모형 전 극패드를 사용했다. 패드는 $0.9 \%$ 식염수를 충분히 뿌린 후 전방머리자세와 목 통증에 직접적인 영향을 미치는 위 등세모근과 목 폄근에 고정하였고, 대상자가 편안하게 앉 은 자세로 대상자에게 “시작 하겠습니다"라는 내용을 전 달하였고, 장치작동하지 않고 환자에게는 치료를 받고 있 음을 인지시켜 플라시보 효과를 유도하였다. 시간은 20 분, 주 3회, 4주 동안 총 12 회를 적용하였다.

\section{측정도구 및 방법}

\section{척추-두개각(Cranial Vertebral Angle)}

전방머리자세를 확인하기 위해 $\mathrm{De}$ 등[10]의 연구를 참 고하여 척추두개각를 측정하였다. 대상자들은 $\mathrm{C7}$ 이 들어 나는 옷을 입고 앉은 자세로 정면을 바라보게 한다. 팔은 자연스럽게 무릎 위에 놓고 목은 자신이 가장 편한 자세 를 유지하게 하였다. 그 후 측면에서 스마트폰 카메라 (Galaxy Note 20, Samsung, korea)를 이용하여 앉은 자 세에서 대상자의 $\mathrm{C} 7$ 에 마킹한 초점을 맞추어 사진을 찍 었으며, 대상자와 카메라 사이의 거리를 일정하게 유지하 기 위하여 카메라를 고정하였다. 그 후 사진에 $\mathrm{CVA}$ 를 측 정하기 위하여 Goniometer를 사용하였다. 사진을 출력하 여 귀의 바깥귀길에서 $\mathrm{C} 7$ 을 연결한 선과 수평선이 이루 는 각도를 측정하였고, 사후에도 동일하게 측정하기 위하 여 노력하였다(Figure 1).

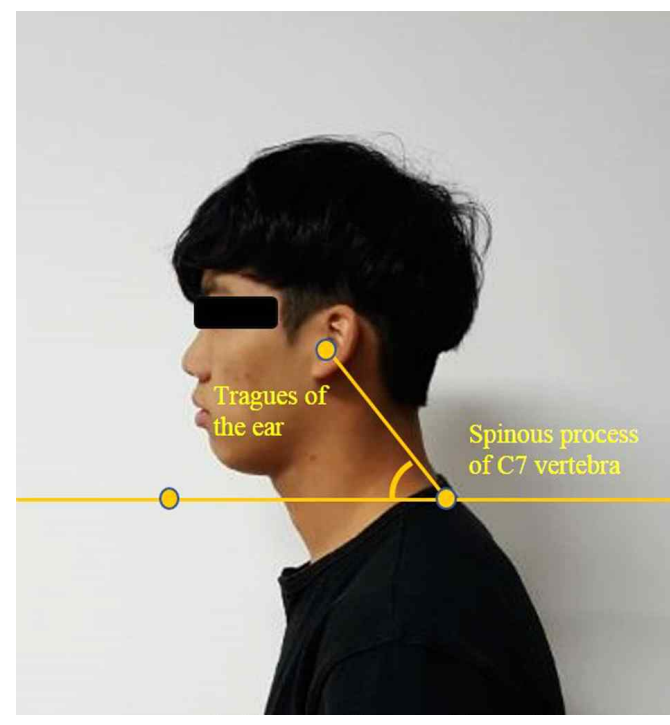

Figure 1. Craniovertebral angle
Raine과 Twomey[4]의 연구에 따르면 급간내 상관계 수(intraclass correlation coefficients)는 높은 신뢰도 (ICC: 0.88)를 보이고 있다. CVA각이 작을수록 $\mathrm{FHP}$ 가 심화된 것으로 판단할 수 있으며, 선행 연구에 따라 $49^{\circ}$ 미만을 FHP로 간주한다.

\section{목 장애지수(Neck Disabilty Index)}

목뼈의 기능을 평가하기 위해 경부장애지수 $(\mathrm{Neck}$ Disabilty Index, NDI)를 사용하였다. 이 도구는 목뼈의 통증 및 불편정도가 일상생활에 어느 정도 장애를 유발하 는지를 알아보기 위한 설문지이며 항목은 총 10 개로, 통증 의 강도, 들어올리기, 집중도, 자기관리, 읽기, 두통, 일, 운전, 수명, 여과 활동으로 구성되어 있다. 항목 당 점수를 0점에서 5점까지 선택할 수 있다. 점수는 이후에 합산하여 총점을 분석할 수 있는데, 34점 초과할 시 완전(Complete), 25 35 중증(severe), $15 \sim 24$ 중등도(moderate), 5 14 약간(mild), $0 \sim 4$ 없음(none)으로 해석한다. 완전은 가장 기능 이 안 좋은 상태를 의미하며 점수가 낮을수록 기능 이 좋음을 의미한다. 본 연구에 서는 환자가 즉각적으로 떠오르는 선지를 선택하게 하였고 재검사시 이전 점수를 알지 못하게 하여 사전에 오류를 방지하였다. 경부장애지 수의 내적 일치도 (Cronbach`s alpha)는 0.88으로 높은 신뢰도를 보인다[12].

\section{삶의 질}

삶의 질을 측정하기 위해 Short form-8(SF-8)를 사용 하였다. Quality Metric, Incorporated(QMI)사에서 의해 개발된 SF-8(Short-Form)은 SF-36을 간단하게 요약하여 환자의 건강관련 삶의 질에 관한 8 개 항목의 설문지로 전 세계적으로 많이 이용되고 있다.

SF-8은 신체적 기능(physical functioning), 일반건강 (general health), 신체의 역할제한(role physical), 감정적 역할제한(role emotional), 통증(bodily pain), 활력 (vitality), 사회 적 기능(social functioning), 정신건강 (mental health), 의 8개 주 요 삶의 질 영역을 측정 하는 포괄적인 건강관련 삶의 질 측정도구이다[13]. 평가는 간 단한 설문으로 되었으며, 문화적인 차이에 영향을 받지 않도록 문항이 개발되었다. 신체적인 측면과, 불안 및 정 서적 측면에 관한 내용이 포함되어 있다[14].

\section{통계방법}

연구의 모든 통계는 SPSS Ver. 20(SPSS Inc., Chicago, USA) 프로그램을 사용하여 산출하였다. 전체 대상자는 동질성 검정과 정규성 검증 방법 중 Kolmogorov-Smirnov 
와 교차분석을 이용 하였다 $(\mathrm{p}>0.05)$. 대상자의 일반적 특 성은 기술통계를 사용하였으며, 모든 측정 자료들이 정규 분포를 보였고, 정규분포를 보였기 때문에 모수적 검정법 을 이용하여 평균값들의 비교를 실시하였다. 집단 간 차 이는 독립표본 $\mathrm{t}$ 검정을 실시하였으며, 각 군의 적용 전, 후간의 유의성을 비교하기 위하여 대응표본 $\mathrm{t}$ 검정을 실시 하였다. 자료의 모든 통계학적 유의수준은 $\alpha=0.05$ 로 설 정하였다.

\section{연구결과}

척추두개각

척추두개각의 변화 차이는 다음과 같다(Table 3). 집단 간의 비교에서는 목안정화 운동군에서 대조군보다 유의한
증가를 보였고 $(\mathrm{p}<0.01)$, 집단 내 전후 비교에서도 목 안 정화 운동이 유의한 변화를 보였다 $(\mathrm{p}<0.05)$.

\section{목 장애지수}

목 장애지수의 변화 차이는 다음과 같다(Table 4). 집 단 간의 비교에서는 목안정화 운동군이 대조군보다 유의 한 감소가 있었고 $(\mathrm{p}<0.001)$, 집단 내 전후 비교에서는 목 안정화 운동군 $(\mathrm{p}<0.001)$ 과 대조군 $(\mathrm{p}<0.05)$ 모두 유의한 변화를 보였다.

\section{삶의 질}

삶의 질 변화 차이는 다음과 같다(Table 5). 집단 간의 비교에서는 목안정화 운동군이 대조군보다 유의한 감소가 있었고 $(\mathrm{p}<0.001)$, 집단 내 전후 비교에서는 목 안정화 운

Table 3. Chang of craniovertebral angle

$(\mathrm{n}=41)$

\begin{tabular}{lllll}
\hline & & Biofeedback $\left(\mathbf{n}_{\mathbf{1}}=\mathbf{2 1}\right)$ & Control $(\mathbf{n}=\mathbf{2 0})$ & $\mathbf{t}[\mathbf{9 5 \%} \mathbf{C I}]$ \\
\hline \multirow{2}{*}{ bVA $\left(^{\circ}\right)$} & paseline & $47.53(0.826)$ & $47.37(1.09)$ & $0.573[-0.437,0.783]$ \\
& change & $2.07(2.76)$ & $47.94(1.36)$ & \\
& $\mathrm{t}$ & $-3.432^{* *}$ & $0.57(1.24)$ & $18.704[0.130,2.858]{ }^{\dagger}$ \\
\hline
\end{tabular}

The values are presented mean $(\mathrm{SD})^{\mathrm{a}}$

CVA: Cranial Vertebral Angle, CI: Confidence interval,

Between the group $\left({ }^{\dagger} \mathrm{p}<0.05\right)$, With in the group $\left({ }^{* *} \mathrm{p}<0.01\right)$

Table 4. Change of neck disability index

$(n=41)$

\begin{tabular}{lllll}
\hline & & Biofeedback $(\mathbf{n}=\mathbf{2 1})$ & Control $(\mathbf{n}=\mathbf{2 0})$ & $\mathbf{t}[\mathbf{9 5 \%} \mathbf{C I}]$ \\
\hline \multirow{3}{*}{$\begin{array}{l}\text { NDI } \\
\text { (Point) }\end{array}$} & baseline & $37.57(1.36)$ & $37.00(2.08)$ & $1.046[-0.533,1.676]$ \\
\cline { 2 - 4 } & Post & $20.29(2.80)$ & $35.8(2.42)$ & $18.704[14.346,17.825]^{\dagger \dagger \dagger}$ \\
\cline { 2 - 4 } & change & $17.29(3.08)$ & $1.2(2.35)$ & \\
\cline { 2 - 4 } & $\mathrm{t}$ & $25.681^{* * *}$ & $2.281^{*}$ & \\
\hline
\end{tabular}

The values are presented mean $(\mathrm{SD})^{\mathrm{a}}$

NDI: Disability Index, CI: Confidence interval.

Between the group $\left({ }^{\dagger \dagger}{ }^{\dagger} \mathrm{p}<0.001\right)$, Within the $\operatorname{group}\left({ }^{*} \mathrm{p}<0.05,{ }^{* *} \mathrm{p}<0.01,{ }^{* * *} \mathrm{p}<0.001\right)$

Table 5. Change of Quality of life

$(\mathrm{n}=41)$

\begin{tabular}{lllll}
\hline & & Biofeedback $(\mathbf{n}=\mathbf{2 1})$ & Control $(\mathbf{n}=\mathbf{2 0})$ & $\mathbf{t}[\mathbf{9 5 \%} \mathbf{C I}]$ \\
\hline \multirow{3}{*}{$\begin{array}{l}\text { SF-8 } \\
\text { (Point) }\end{array}$} & baseline & $76.57(4.97)$ & $78.95(3.86)$ & $-1.707[-5.198,0.441]$ \\
\cline { 2 - 5 } & Post & $78.95(3.85)$ & $81.40(3.09)$ & $4.855[0.392,9.549]^{\dagger \dagger}$ \\
\cline { 2 - 5 } & change & $9.19(3.34)$ & $2.45(5.37)$ & \\
\cline { 2 - 5 } & $\mathrm{t}$ & $-12.606^{* * *}$ & -2.042 & \\
\hline
\end{tabular}

The values are presented mean $(\mathrm{SD})^{\mathrm{a}}$

SF: Short Form, CI: Confidence interval.

Between the group $\left({ }^{\dagger \dagger} \mathrm{p}<0.001\right)$,Withinthegroup $\left({ }^{*} \mathrm{p}<0.05,{ }^{* *} \mathrm{p}<0.01,{ }^{* * *} \mathrm{p}<0.001\right)$ 
동군 $(\mathrm{p}<0.001)$ 이 유의한 변화를 보였다.

\section{고찰}

현대사회의 수많은 직업 특성상 장시간의 컴퓨터 사용 과 자동차 운전 등 구부정한 동작 수행을 하게 되는 상황 이 발생한다. 이로 인해 목이 전방으로 과도하게 돌출되 는 전방머리자세를 쉽게 유발되며 이는 대표적인 목정렬 이상 중 하나이며 이런 자세는 신체에 다양한 근골격계적 인 질환을 일으키게 된다.

본 연구에서는 전방머리자세의 개선이 실질적으로 목 의 기능장애 해소와 기능장애 해소에 따른 삶의 질 변화 를 알아보기 위해 연구를 진행하였으며 목안정화 운동이 전방머리자세 개선에 효과를 보였다.

Roddey 등[15]에 따르면 4주간의 목 폄 근력강화 운 동을 한 운동군에서 전방머리자세의 뒤당김이 증가하였 고, Cesar 등[16]의 연구에서 바이오 피드백을 활용하여 운동을 시켰을 때 효과적으로 전방머리자세를 감소 시킬 수 있었다.

바이오피드백 훈련은 환자 스스로 보며 교정하는 단계 를 거처 올바른 자세를 인지함으로써 일정 시간이 지난 후에도 기억한 자세를 기억한 것으로 보인다. Trewartha 등[17]의 실험에서 블록 맞추기를 수동적으로 진행한 방 법으로 훈련한 경우보다 활동적인 방법으로 훈련한 경우 고유수용성 교정이 유의한 차이 $(\mathrm{p}=0.007)$ 가 있었다. 본 연구에서 아마도 목 안정화 운동이 스스로 교정한 단계에 서 고유수용성 교정의 향상되어 올바른 자세를 유지한 것 으로 사료된다. 또한 Dusunceli 등[18]의 연구에서는 55 명의 만성 목 통증 환자에게 목 안정화 운동을 적용하였 고 12 개월 후에도 통증 및 목 기능향상에 가장 유의한 차 이가 나타났다고 보고하였다. 이런 선행연구를 종합해 봤 을 때 본 연구에서도 목안정화 운동을 통하여 전방머리자 세가 개선되었고 $(\mathrm{p}=0.033)$, 전방머리자세가 개선됨에 따라 목 기능향상에 유의한 효과를 보인 것으로 생각된다. 그 러나 대조군에서 또한 유의한 효과를 보였다. Moerman[19] 에 의하면 중재에 대한 신뢰성이 확보 된다면 편도체의 활성도 증가로 옥시토신과 편도체의 수용체와 결합하여 오피오이드 관련 위약반응이 증가한다고 하였다. 대조군 에서도 유의한 효과를 보인 이유는 실험 동안 목에 치료 를 받았다는 생각 때문에 목의 불편감이 일부 해소됐다라 고 느꼈을 플라시보 효과라고 생각된다. 더욱 정확한 결 과를 확인하기 위해 향후 연구에서는 전방머리자세와 목 의 기능에 관련된 상관연구가 진행될 필요가 있을 것이다.

본 연구에서 목 안정화 운동그룹에서 삶의 질 향상을 보였으며, 이는 전방머리 자세를 개선함에 따라 목의 기 능장애를 향상시켜 삶의 질을 향상시킨 것으로 생각된다.
결론

본 실험은 전방머리자세의 개선에 따른 목의 기능과 삶 의 질의 변화를 알아보기 위해 연구를 진행하였으며, 전 방머리자세와 삶의 질에는 전방머리자세 개선에 따라 유 의한 차이가 있었으며, 목의 기능은 전방머리자세 개선과 다르게 두 그룹 모두 유의한 효과를 보였다. 전방머리자 세의 향상은 목 기능장애와 삶의 질에 효과적인 중재방법 이 될 수 있다.

\section{Acknowledgement}

본 논문은 2021년도 광주보건대학교 교내연구비의 지 원을 받아 수행된 연구임(No. 2021015)

\section{참고문헌}

1. Kim Y, Kang M, Kim JW, Jang JH, Oh J. Influence of the Duration of Smartphone Usage on Flexion Angles of the Cervical and Lumbar Spine and on Reposition Error in the Cervical Spine. Phys Ther Kor. 2013;20:10-7.

2. Lipchik G, Holroyd K, France C, Kvaal S, Segal $\mathrm{D}$, Cordingley $\mathrm{G}$, et al. Central and peripheral mechanisms in chronic tension-type headache. Pain. 1996;64:467-75.

3. Griegel-Morris P, Larson K, Mueller-Klaus K, Oatis C. Incidence of common postural abnormalities in the cervical, shoulder, and thoracic regions and their association with pain in two age groups of healthy subjects. Phys Ther Kor. 1992;72:425-31.

4. Raine S, Twomey L. Head and shoulder posture variations in 160 asymptomatic women and men Arch Phys Med Rehabil. 1997;78:1215-23.

5. Henderson C. Myofascial Pain and Dysfunction: The Trigger Point Manual. J Can Chiropr Assoc. 1984;28:341.

6. van Duijn J, van Duijn A, Nitsch W. Orthopaedic manual physical therapy including thrust manipulation and exercise in the management of a patient with cervicogenic headache: a case report. J Man Manip Ther. 2007;15:10-24.

7. Cho W, Lee W, Choi H, An investigation on the biomechanical effects of turtle neck syndrome through EMG analysis. Proceedings of the Korean 
Society of Precision Engineering Conference; 2008.

8. Shin D. The effects of a deep cervical flexion exercise on neck-shoulder pain, muscle strengthening, and cervical alignment in sedentary workers. Sahmyook University 2008.

9. Yoo W, Yi C, Cho S, Jeon H, Cynn H, Choi H. Effects of the height of ball-backrest on head and shoulder posture and trunk muscle activity in VDT workers. Industrial health. 2008;46:289-97.

10. De-La-Llave-Rincó A, Fernádez-De-Las-PeÑs C, Palacios-CeÑ D, Cleland J. Increased forward head posture and restricted cervical range of motion in patients with carpal tunnel syndrome. J Orthop Sports Phys Ther. 2009;39:658-64.

11. Ferreira P, Ferreira M, Maher C, Herbert R, Refshauge K. Specific Stabilisation Exercise For Spinal And Pelvic Pain: A Systematic Review. J Orthop Sports Phys Ther. 2007;37:422.

12. Lee H, Nicholson L, Adams R, Maher C, Halaki $\mathrm{M}$, Bae S. Development and psychometric testing of Korean language versions of 4 neck pain and disability questionnaires. Spine. 2006;31:1841-5.

13. Behrman A, Light K, Flynn S, Thigpen M. Is the functional reach test useful for identifying falls risk among individuals with Parkinson's disease? Arch Phys Med Rehabil. 2002;83:538-42.

14. Lefante J, Harmon G, Ashby K, Barnard D, Webber L. Use of the SF-8 to assess health-related quality of life for a chronically ill, low-income population participating in the Central Louisiana Medication Access Program (CMAP). Qual Life Res. 2005;14:665-73.

15. Kibler W, Ludewig P, McClure P, Michener L, Bak K, Sciascia A. Clinical implications of scapular dyskinesis in shoulder injury: the 2013 consensus statement from the 'Scapular Summit'. Br J Sports Med. 2013;47:877-85.

16. Fernádez-de-las-Peñs C, Péez-de-Heredia M, MoleroSáchez A, Miangolarra-Page J. Performance of the craniocervical flexion test, forward head posture, and headache clinical parameters in patients with chronic tension-type headache: a pilot study. J Orthop Sports Phys Ther. 2007;37:33-9.

17. Trewartha K, Case S, Flanagan J. Integrating actions into object location memory: A benefit for active versus passive reaching movements. Behavioural brain research. 2015;279:234-9.

18. Dusunceli Y, Ozturk C, Atamaz F, Hepguler S, Durmaz B. Efficacy of neck stabilization exercises for neck pain: a randomized controlled study. J Rehabil Med. 2009;41:626-31.

19. Moerman DE. Edible symbols: The effectiveness of placebos. Annals of the New York Academy of Sciences. 1981;364:256-68. 